\title{
DESAFIOS DO ENSINO JURÍDICO NO BRASIL NO SÉCULO XXI: METODOLOGIA TRADICIONAL VERSUS METODOLOGIA PARTICIPATIVA
}

\author{
Denise Almeida de Andrade* \\ Laís Sales Biermann*
}

\begin{abstract}
RESUMO
O presente artigo busca analisar os métodos de ensino participativo, a partir de uma análise comparativa com o modelo tradicional-expositivo de ensino. Nessa perspectiva, será estudado modelo de aprendizagem ativa, e posteriormente, a sua influência no alcance de uma estrutura educacional mais democrática. As novas exigências sociais e educacionais serão contextualizadas ante a Globalização e a Pandemia atual, ponderando as contribuições e os desajustes encontrados nesse contexto. Por fim, elencará cinco métodos de ensino participativo, refletindo, após, a respeito do modelo pedagógico ideal para o século XXI. Neste trabalho foi empregada pesquisa teórico-bibliográfica e documental, sendo a abordagem qualitativa.
\end{abstract}

Palavras-chave: Ensino jurídico. Métodos participativos. Globalização. Pandemia. Desafio

\section{CHALLENGES OF LEGAL EDUCATION IN BRAZIL IN THE 21st CENTURY: TRADITIONAL METHODOLOGY VERSUS PARTICIPATORY METHODOLOGY}

\begin{abstract}
This article seeks to analyze the methods of participatory teaching, from a comparative analysis with the traditional-expository model of teaching. In this perspective, an active learning model will be studied, and later, its influence in reaching a more democratic educational structure. The new social and educational requirements will be contextualized in the face of Globalization and the current Pandemic, considering the contributions and mismatches found in this context. Finally, it will list five methods of participatory teaching, reflecting, later, on the ideal pedagogical model for the 21 st century. In this work, theoretical-bibliographic and documentary research was employed, with a qualitative approach.
\end{abstract}

Keywords: Legal education. Participatory methods. Globalization. Pandemic. Challenge

\footnotetext{
${ }^{*}$ Doutora e Mestre em Direito Constitucional. Pós Doutora em Direito Político e Econômico. Professora do Mestrado Acadêmico e Graduação em Direito da Unichristus. Professora da FGVLaw SP. E-mail: andradedenise@hotmail.com

* Mestranda em Direito pela UNICHRISTUS. Pós-graduada em Direito e Processo do Trabalho pela Universidade ANHANGUERA. Graduada em Direito pela Universidade de Fortaleza (UNIFOR/CE). Advogada. E-mail: laisbiermann@hotmail.com.
}

Revista de Pesquisa e Educação Jurídica | e-ISSN: 2525-9636 | Encontro Virtual | v. 7 | n. 1 | 


\section{INTRODUÇÃO}

Em uma realidade na qual o modelo tradicional-expositivo de ensino ainda se revela predominante, surge o desejo pelo estabelecimento de novos métodos de ensino, que prestigiem as experiências dos discentes e confira maior significado à sala de aula, permitindo a valorização da individualidade e dos interesses dos alunos. Essa proposta confere maior relevância às intervenções produzidas pelos discentes no ambiente acadêmico e, consequentemente, que são conduzidas e contextualizadas pelo docente, que mantém sua relevância e seu papel no ensino jurídico.

Neste artigo, os métodos de ensino participativo representarão o centro das discussões, não se furtando de abordar as mudanças sociais que ensejaram a necessidade de desenvolvimento do novo paradigma pedagógico, além das dificuldades enfrentadas pelo ensino jurídico. Essa discussão ganha força também quando, nesse momento, completa-se um ano da pandemia do coronavírus, de acordo com informação da Organização Mundial da Saúde - OMS. Nesse período, o uso das tecnologias, que já se mostrava intenso na sociedade moderna, recebeu considerável importância, tendo em vista a necessidade de adequação aos novos modos de se ensinar, trabalhar, reunir e festejar.

De início, trataremos sobre o método tradicional de ensino, abordando definição, características, bem como as consequências de uma prática pedagógica conservadora, desassociada de preocupação com necessidades deste século. Em seguida, faremos uma breve digressão histórica das relações sociais, indicando algumas demandas da contemporaneidade, as quais têm estreita relação com os avanços tecnológicos das últimas 5 décadas, a exemplo da internet.

Os métodos de ensino servem para orientar os discentes que buscam o conhecimento, sendo de grande valia na formação dos futuros profissionais. Entretanto, para que tal intento se concretize faz-se necessário assegurar a utilidade desses mecanismos, obedecendo as premissas estruturantes da educação, como o sentimento de empatia e o aperfeiçoamento didático. Por fim, a última parte explorará os métodos de ensino participativo, adentrando na definição e nas as especificidades de cada um. As espécies selecionadas para esse estudo foram: o diálogo socrático, o método do caso, o role-play, a simulação e o PBL. 
Discutiremos o uso desses métodos de forma a comparar seus resultados com a metodologia tradicional, refletindo acerca do atual desafio encontrado pelas instituições acadêmicas na construção da forma mais adequada e inclusiva de aprendizagem. A maneira conservadora de ensinar, bem como as suas contribuições para o mundo acadêmico e os percalços encontrados atualmente na manutenção desse método, serão discutidos e receberão críticas e sugestões visando à entrega de um devido ensino jurisdicional. Para esse fim, buscará diferenciar o paradigma educacional ainda predominante na nossa sociedade, qual seja, o modelo tradicional de ensino, daquele em crescente desenvolvimento, oriundo das evoluções sociais e tecnológicas o modelo participativo de ensino - e ato contínuo, averiguar os reflexos educacionais resultantes de cada abordagem.

\section{O TRADICIONAL MODO DE ENSINAR}

A evolução humana pode ser entendida como um fenômeno oriundo do desenvolvimento de vários atos, dentre eles o ato de se alimentar e o ato de se comunicar. Este, especificamente, permitiu a interação entre as pessoas, possibilitando a concepção de outros indivíduos, a proteção familiar e até a transação e a realização de negócios, desenvolvendo assim a figura da sociedade.

O papel da linguagem na construção de um discurso ou de um texto mostra-se fundamental para que os receptores de informações consigam atingir a mensagem pretendida pelo transmissor (MACHADO, 2009). Salienta-se, então, que o objeto do ofício do professor constitui uma atividade complexa, visto que abrange não apenas a difusão do saber, mas principalmente a construção de um ambiente adequado ao desenvolvimento da capacidade discente, oferecendo o suporte necessário para a plena aprendizagem (MACHADO, 2009). Nessa lógica, para proporcionar esse contexto, busca-se, portanto, incentivar o exercício de práticas cognitivas, como a leitura, a tradução, a análise conjunta, o debate e as indagações, bem como a interpretação de determinado tema, sendo consideradas algumas dessas situações, por muitos anos, atuações externas à docência.

Educação, segundo PIMENTA e ANASTASIOU (2017, p.97), "é um processo de humanização", transformando não apenas a sociedade em geral, mas cada pessoa 
individualmente. A inserção do sujeito na sociedade, desde a mais tenra idade até os anos de fase adulta é um desafio tanto no âmbito das relações privadas quanto no âmbito público, da escola, universidade, relações profissionais etc. Nesse sentido, para Cristina Dias Allessandrini (2002, p.157), a função do profissional da educação traduz-se em "qualificar o diálogo entre as inúmeras questões que vivenciamos em nosso cotidiano, com cada tema abordado no decorrer de palestras, textos e livros que nos auxiliam na compreensão dos mecanismos invisíveis atuantes no processo."

A preocupação neste artigo, contudo, se refere ao ensino superior do Direito, compreendido como uma ciência, e como tal a produção do conhecimento científico acerca de determinada temática não equivale apenas acessar dados e obter informações, é preciso agregar elementos como a interpretação, a contextualização, o debate e a organização de ideias e opções metodológicas (PIMENTA; CAMARGOS, 2017), a fim de que referido conhecimento seja, de fato, significativo, impacte na mudança de problemas reais e seja constituído em bases científicas sólidas que autorizem, inclusive, a avaliação crítica dos parâmetros utilizados.

É neste cenário que se analisará como o modus de experienciar a docência e a opção por determinados métodos de ensino - o processo de ensino aprendizagem - tem sido um desafio, na medida em que novas exigências e realidades são percebidas no cenário atual. Antes desse exame, cabe anunciar que não é de hoje que essa inquietação dos críticos de ensino se faz presente, sendo algo frequente, no Brasil, desde o surgimento das primeiras instituições jurídicas nacionais de ensino superior (LIMA, 2018). A reflexão acerca da formação dos profissionais do Direito geralmente passa pela qualidade e eficácia da maneira de ensiná-los, as finalidades almejadas pela Academia e pelas habilidades inatas ou apreendidas de cada indivíduo (LIMA, 2018).

O professor, nesse caso, servirá como uma ponte entre a informação e o conhecimento, figurando como um facilitador da aprendizagem e auxiliando os aprendizes a se desenvolverem profissionalmente ao concluírem o curso (PIMENTA; ANASTASIOU, 2017). Deve-se, portanto, admitir que a análise e o reconhecimento da forma como se ensina, isto é, da metodologia, compõe, na prática da docência, elemento essencial na construção do conhecimento (GHIRARDI, 2012). 
José Garcez Ghirardi e Juliana Ferrari de Oliveira (2016, p. 387) narram que a transformação deve acontecer internamente, pois

\begin{abstract}
A mudança pretendida para a aula jurídica requer também o compromisso de o docente se reconhecer em constante aprendizagem, sabendo que essa trajetória é infinita, mas não solitária e independente. Nesse sentido, essa alteração de perspectiva solicita ainda participação, vontade e compromisso de todos os envolvidos no processo educacional e, em especial das instituições de ensino, corresponsáveis pela formação continuada dos professores de ensino superior.
\end{abstract}

Pode-se afirmar que o modo de aprendizagem se encontra intrinsicamente vinculado à forma como recebemos, um dia, o conhecimento pelos nossos mestres, revelando, portanto, a presença do elemento da tradição. Todavia, faz-se fundamental adicionarmos a esse fator um sentimento basilar na construção do conhecimento, qual seja, a empatia. Dessa forma, não representa atitude legítima o aprisionamento em antigas e, muitas vezes, ineficazes, práticas de ensino em prol de um conservadorismo pedagógico, devendo permanecer somente por vislumbrar contribuições no ambiente discente (ALLESSANDRINI, 2002).

Há tempos, ainda no século XIX, o modelo brasileiro adotava o mesmo padrão visto na Faculdade de Coimbra, aquele no qual a hierarquia e a comunicação unilateral eram tidas como as únicas formas de condução de uma aula. Já no século seguinte, o que se indagava era a ausência de vinculação da docência jurídica com o viés prático existente, refutando uma abordagem unicamente doutrinária do curso de Direito, fato que pode ser constatado com a obrigatoriedade de realizar o Exame de Ordem apenas no ano de 1996 (LIMA, 2018).

O método tradicional de ensino, demonstrado pelo filme The Paper Chase, caracterizase por ser rigoroso, hermético e supervalorizar a hierarquia do docente, como vetor de uma verdade absoluta (GHIRARDI, 2012). A maneira impositiva de apresentar ideias e conteúdos, muitas vezes, desconsiderando as dúvidas encontradas pelos alunos, por acreditar serem incoerentes, ou evitando o diálogo com eles, afasta do magistério a noção de consenso, premissa básica de uma sociedade plural e que se autodenomina democrática (GHIRARDI, 2012). Assim, é clara a ocorrência do fenômeno da dissonância cognitiva nesse professor e consequentemente do viés de confirmação, resposta psíquica automática para solucionar o embate entre as crenças e 
ideias elaboradas pela mente humana e as condutas praticadas (FERNANDEZ; FERNANDEZ, 2017).

Em uma proposta conservadora, o discente é o ignorante e o docente o detentor do conhecimento. Os fatos reais, bem como as particularidades de cada sujeito, dentre elas a condição social e a raça, tornam-se insignificantes, revelando uma postura arrogante e egoísta (GHIRARDI, 2012). Dado isso, a empatia e a oportunidade de construção colaborativa, habilidades que vêm ganhando força nas relações profissionais e nos relacionamentos interpessoais, não encontram um locus adequado no clássico modo de aprendizagem. Ghirardi (2012, p.33) compara ainda essa relação vertical com o processo de transferência de arquivos de computador, ao afirmar que: "Primeiro é preciso formatar a unidade que receberá a informação, isto é, capacitá-la a entender a linguagem em que se inscrevem os dados para, depois, transmitir todo o conteúdo. Em nosso caso, a unidade receptora é o cérebro humano". A analogia entre a sala de aula e um protocolo de computação, repetitivo, automatizado e acrítico, confirma o desalinho entre a escolha pelo uso, exclusivo, de um método de ensino tradicional e as necessidades que as relações do século XXI demandam.

Para muitos, não há outra forma de transmitir conhecimento jurídico senão pela simples exposição das normas, teses, doutrinas e ensinamentos consolidados. Assim, o chamado "ensino bancário", expressão cunhada pelo professor Paulo Freire, consolidou-se nos cursos de Direito e caracteriza-se quando “(...) o professor tem a intenção de "depositar" o conhecimento na cabeça do aluno para que, passivamente, o receba, e onde o professor, posteriormente, por meio da avaliação vai tirar um “extrato” dos depósitos feitos (ALENCAR; SALES, 2014).”

Essa espécie de extrato equivale nada mais que uma representação dos pensamentos expressados pelos docentes, sem a avaliação do senso crítico dos alunos, como seres humanos que são e por isso, pensantes. A sociedade moderna exige do cidadão, futuro profissional do mercado de trabalho, não apenas a mera repetição de ideias transmitidas por alguém, mas também a elaboração de estratégias e novos caminhos para a resolução dos problemas encontrados, tornando a iniciativa, a criatividade e a eficiência valores fundamentais. 
Outro aspecto que merece destaque nesse modelo de ensino unidirecional é o parâmetro único de avaliação, por meio de uma prova-teste, por meio da qual o conteúdo ministrado deve ser apreendido e compilado, a fim de que o/a discente esteja apto a realizar um exame objetivo, por meio de assertivas, a partir das quais haverá a quantificação do que "foi absorvido" pelo aluno, atribuindo-se uma nota equivalente à porcentagem de acertos e de erros (GHIRARDI, 2012). Sabemos que a avaliação é um tema complexo, que ainda não conseguimos superar a prova-teste, por outro lado, é possível realizar atividades paralelas que possam compor um conceito/uma nota ao final, sem estar preso a uma verificação datada e exclusiva. Neste ponto, entendemos que utilizar um único meio para aferir os ganhos dos/das discentes é uma escolha limitada, pois desconsidera a possibilidade de imprevistos/intempéries do dia do exame, não prestigia a observação ao longo das aulas, desestimula a participação ativa nas atividades propostas ao longo do semestre/ano etc.

Com o advento da Constituição Federal de 1988, o pensamento de uma educação mais democrática e em conformidade com os princípios constitucionais, passou a crescer na realidade social, unindo ao ensino a pesquisa e a extensão (LIMA, 2018). O ensino jurídico deveria prestigiar o conjunto de experiências docente e discente, o que viabiliza uma reflexão múltipla e mais crítica dos problemas e da situação existente, uma visão sistêmica dos cenários apresentados, o que se contrapõe a um modelo de ensino estratificado e pouco flexível.

\section{O AVANÇO DA SOCIEDADE E A NECESSIDADE DE MUDANÇA DOS MÉTODOS DE ENSINO JURÍDICO}

Embora existam vários entendimentos a respeito dos atributos da globalização, é possível indicar alguns pontos comuns a todos eles, quais sejam: a contenção das barreiras mercadológicas, o aumento da concorrência nos campos laborais, a relativização da integridade estatal e o conflito entre a uniformização e a desintegração cultural, frente o aparecimento de ideias locais (BURBULES; TORRES, 2000).

No âmbito da educação superior, a competitividade entre as instituições revela-se como um dos principais efeitos do momento, podendo gerar gastos elevados com a aprendizagem, na medida em que se percebe uma intensa corrida das instituições de ensino para o aperfeiçoamento e inovação de suas técnicas (BURBULES; TORRES, 2000). 
Os reflexos do ensino, nesse período, trazem aspectos positivos e negativos para a realidade, porquanto concretizam as noções de democracia, pluralidade, respeito à diversidade e autonomia e liberdade de pensamento, mas também toleram o distanciamento do professor das peculiaridades da vida de cada discente, característica típica do ensino tradicional (BURBULES; TORRES, 2000). Diante desse panorama, surgem novas discussões a respeito do melhor modo de ensinar e

Nesses debates, os proponentes do modelo tradicional são frequentemente acusados de
oferecer um ensino ineficaz e alienante, tendente a reproduzir e reforçar os mecanismos
de dominação hierárquica que estruturam a sociedade; além disso, são acusados de tolher
a criatividade e a imaginação em nome do conformismo e da padronização. Os que
defendem modelos alternativos, por sua vez, são taxados de propor um ensino sem
substância, de adotarem uma visão equivocada da individualidade como valor absoluto,
que impede a efetiva transmissão intergeracional do saber; são também acusados de
potencialmente formar ignorantes autocomplacentes, incapazes de atuar produtivamente
no âmbito coletivo. (GHIRARDI, 2012, p.43)

Um dos desafios para o ensino jurídico, às vésperas de começarmos a terceira década do século, é estabelecer e implementar uma prática pedagógica mais sensível ao contexto global, às necessidades humanas, às exigências do mercado profissional; entendemos que alocar o aluno no centro do processo de ensino aprendizagem é um caminho (GHIRARDI, 2012). O olhar que prioriza o conhecimento e a vivência prévios dos discentes e as contribuições de cada um em sala de aula se situa no espectro dos métodos participativos (GHIRARDI, 2012).

Entendemos que a conciliação entre o método tradicional/expositivo e os métodos de ensino participativo é a opção mais adequada, em curto e médio prazo. A combinação entre as duas abordagens se mostra factível e produtiva: factível porque não exige mudanças em projetos pedagógicos de curso, nas instalações físicas das IES, na alteração significativa dos quadros docentes e produtiva porque reconhece que o ensino jurídico precisa estar alinhado às demandas diuturnas da sociedade, à complexidade dos problemas que surgem no cotidiano.

Ao optarmos pelo método tradicional/expositivo de ensino, temos a premissa de que o conhecimento decorre de um procedimento direto de aferição, uma vez que é absorvido mediante aulas ministradas por um docente, sendo o/a aluno/a, ao final avaliado/a, por exames escritos, os quais exigem a compreensão dos conteúdos estudados. A escolha por métodos participativos como ferramenta para a consecução dos objetivos estabelecidos pelo/a docente, há uma espécie 
de curadoria de informações, de condução do processo de ensino aprendizagem, não se restringindo ao conteúdo da disciplina.

O novo papel do docente na sociedade parte do pressuposto de que a troca bilateral de experiências entre os sujeitos participantes da relação de ensino alcança grande relevância, traduzindo que aquele que, tradicionalmente, recebe conhecimento também está apto a contribuir, a sua maneira, com o docente (GHIRARDI, 2012). O aluno, ao chegar em uma instituição de ensino, traz consigo não apenas a perspectiva de aprender e de concluir o ciclo da graduação com o diploma de bacharel, mas também, suas vivências, suas crenças pessoais e suas concepções construídas no decorrer de sua história (PERRENOUD, 2000).

Nesse sentido, a expectativa por um espaço de discussão plural mostra-se cada vez mais frequente, nas escolas e universidades, capacitando pessoas para refletirem e interpretarem os temas analisados, com base das vivências do dia a dia, resolverem impasses complexos, e incentivarem o diálogo e a participação entre os sujeitos do processo educacional (PERRENOUD, 2000). É interessante aduzir, porém, que para a construção de um caminho para tal inovação, as capacidades e aptidões do educador devem consistir nas primeiras questões analisadas.

É nesse momento que o estudo das competências e habilidades ganha força (DEMO, 2012). Embora existam autores que entendam que esses termos se confundem, como é o caso do Philippe Perrenoud, pensa-se que a melhor percepção seja a da existência de diferenças entre ambos (DEMO, 2012). As habilidades estão relacionadas à criação de oportunidades, frente às condições factuais presentes, para se atingir certo objetivo; já as competências estão mais vinculadas à ideia de competição, o que se alinha a uma visão mais individualista, muitas vezes afastada do caráter social das relações entre as pessoas (DEMO, 2012).

É a partir da interpretação particular de cada pensador que se define as suas habilidades mais notáveis e, partir daí, as metodologias adequadas ao seu perfil (DEMO, 2012). Nota-se, com isso, que há muito do docente em sua maneira como ministra aula, sendo difícil afirmar que se consegue separar essas duas esferas interligadas das nossas vidas: o pensar e o agir. 
Pode-se ainda imaginar que as habilidades correspondem a dons pessoais, inerentes à sua natureza ou, pelo menos, obtidas nos primeiros anos de vida, período em que a personalidade do sujeito está sendo formada, entretanto, essa reflexão apresenta-se incompleta. A constatação de que o aprendizado das habilidades ocorre mesmo após as primeiras fases de nossa vida, ao mesmo tempo que proporciona esperança, gera ansiedade, dado que por passar a existir e se transformar no diferencial da vida acadêmica, aproxima essa capacidade do conceito de competência. (DEMO, 2012).

Convém sintetizar, nessa perspectiva, que uma razoável reflexão que poderia ser feita para que as mudanças, no processo de ensino, possam se desenvolver seria o aperfeiçoamento do sentimento de empatia e paciência. A inclusão da interdisciplinaridade, de forma mais atuante dos ensinamentos da psicologia e da sociologia, certamente facilitaria a conquista desse feito, oportunizando o surgimento das metodologias de ensino conhecidas por participativas.

\section{O DESAFIO DA ADOÇÃO DOS MÉTODOS PARTICIPATIVOS NO DIREITO}

Preliminarmente, pode-se aduzir que a identidade do modo de ensino de um conteúdo parte de um processo de seleção baseado em três perguntas: o que se deseja ser estudado, como se ensina o objeto escolhido e a quem ele será lecionado (GHIRARDI, 2012). A reunião das respostas desses questionamentos constituirá uma espécie de padrão a ser adotado quando se pretender a indicação do método mais apropriado de ensino para elucidar determinada situação.

Buscar responder essas três indagações seria o caminho mais assertivo para um processo de aprendizagem norteado pelo protagonismo discente. As informações e conteúdos têm importância, na medida em que, encontram significado nas experiências do grupo, na partilha construtiva e na capacidade do docente de mediar esse processo. Percebe-se, entretanto, que, antes de tudo, ao focar a atenção e os esforços na pessoa do aluno, nas suas facilidades e dificuldades, o método de ensino estaria sendo diretamente escolhido ou construído. Logo, assim como acontece nas relações sociais em geral, a comunicação interpessoal só flui, de modo eficaz, quando se age e dialoga com um indivíduo consoante a sua personalidade e o seu temperamento, havendo, portanto, várias linguagens a ser adotada a depender dos fatores subjetivo e temporal. 
Sabendo disso, outra dificuldade é imposta quando decidimos enfrentar o estabelecimento da metodologia, sendo necessário distinguir as perspectivas do objeto de ensino, podendo estas serem vinculadas a sua natureza, à prática ou à percepção em relação à realidade (GHIRARDI, 2012). Trata-se dos diversos ângulos do conhecimento. Mesmo que possamos escolher trabalhar com apenas um deles no processo de aprendizagem, o ideal seria a união das três dimensões, pois assim estaríamos construindo um método completo e íntegro (GHIRARDI, 2012).

Imagine-se, por exemplo, que você aceite o convite realizado por uma instituição de ensino jurídico para ministrar aulas sobre Direito do Consumidor. Em seguida, você opta por ensinar a parte prática dessa disciplina, que será desenvolvida em um escritório institucional especializado. Ao concluir essas etapas básicas, será iniciado a elaboração do plano de ensino, do qual constará os conteúdos, a quantidade de horas adequadas para cada aula e as literaturas referentes ao tema, caso precise. Embora pareça fácil a execução desse plano em um primeiro momento, para que se atinja a efetividade almejada, é importante uma minuciosa organização no sentido enquadrar, para cada aula, uma atividade correspondente (GHIRARDI, 2012).

Os métodos de ensino participativo, como o próprio termo aduz, consistem em instrumentos pedagógicos, inclusivos e independentes, capazes de provocar a criticidade, a resolutividade e a iniciativa do discente (FRANCO; COSTA FILHO, 2017). Essas técnicas embora apresentem atributos próprios e as suas particularidades, encontram pontos em comum na interação e contribuição pelos próprios interessados na aprendizagem, assim como traduzem novas visões de regência das aulas (PEREIRA JÚNIOR; MELO, 2018). Nesse artigo científico serão abordadas cinco espécies: o diálogo socrático, o método do caso, o role-play, a simulação e o método baseado em problemas.

O método denominado diálogo socrático, apesar de referir-se ao famoso comportamento insistente de Sócrates, pensador da Grécia Antiga, é ainda hoje desconhecido por muitos (GHIRARDI, 2012). A estratégia adotada por ele corresponde à realização de questionamentos como forma de respostas às dúvidas levantadas pelos estudantes (GHIRARDI, 2012). Essa técnica estimula a desenvoltura e a capacidade criativa e dedutiva do aprendiz, 
porquanto caracteriza-se por alcançar o seu objetivo - o conhecimento - indiretamente. Apesar de o recurso da indisponibilidade direta da resposta ao discente demandar um maior esforço, quando comparamos com a aula expositiva, ele permite elevada fixação do conteúdo, sendo melhor absorvido.

A ideia orientadora dessa via retrata nada menos que a noção de autoconstrução, o que significa que é inadmissível a rápida entrega da solução à questão, sendo que a forma devida estaria na adoção do processo lento de construção do conhecimento, com o auxílio de facilitadores (GHIRARDI, 2012). O principal atrativo dessa metodologia é a ausência de discursos impositivos, nos quais parecem concretizar a manutenção de uma única verdade, aquela expressada pelos docentes (PEREIRA JÚNIOR; MELO, 2018). Já no que concerne aos seus pontos negativos, vale mencionar que a realização de perguntas durante a maior parte do tempo pode intimidar os alunos mais retraídos, gerando temor em comparecer à sala de aula, como também aparentar carência de preparação do roteiro de aula e, até mesmo, certo despreparo do professor para exercer às suas funções, tornando insegura a confiança depositada pelo aluno ao mestre (PEREIRA JÚNIOR; MELO, 2018).

Nota-se ainda que em uma sociedade como a nossa, diariamente conectada na internet e, ansiosa, devido à pressa com a qual a realidade competitiva enfrenta, aqueles que desejam o conhecimento costumam ser impacientes e evitar esse tipo de método, buscando substituí-lo pela tradicional forma expositiva.

Há duas espécies de diálogo socrático, o de sentido estrito, pouco preocupado com os conceitos em si, e o de sentido amplo, cujo foco, apesar de serem as definições de institutos da disciplina, tem esse fim como consequência, não como análise inicial (GHIRARDI, 2012). Vale ressaltar ainda que, apesar de consistir em mecanismo de ensino em que o aluno se destaca, o método em debate não enfatiza necessariamente o cotidiano das pessoas (GHIRARDI, 2012).

O método do caso, quando aplicado ao ensino jurídico, corresponde, prioritariamente, ao exame de decisões reais oriundas do Poder Judiciário, estimulando, com isso, o pensamento crítico dos alunos sobre a matéria tratada, assim como oportunizando, ainda que em menor escala, o contato deles com o lado prático do Direito (GHIRARDI, 2012). 
O objeto de estudo não é a conceituação ou formulações doutrinárias a respeito da teoria do Direito, mas sim a ordem produzida pelos magistrados e regulada pelo ordenamento jurídico, que viabiliza, dentro da análise de um caso concreto/real, a discussão sobre institutos jurídicos e teorias. Assim, é possível afirmar que o processo do conhecimento partirá de uma decisão judicial, passará pelo desenvolvimento crítico para, ao final, descortinar os institutos legais. (GHIRARDI, 2012).

O método role-play apresenta-se como uma espécie de ensaio da feitura de atividade jurídicas, em que o envolvido se vê realizando atos oficiais (na função de magistrados, membros do Ministério Público, da Defensoria Pública etc.) (GHIRARDI, 2010). A assunção de um posicionamento específico, em conformidade com a orientação do docente, objetiva muito além de mero conhecimento do conteúdo, pois se ocupa em motivar outras perspectivas integrantes do ato educacional, como a capacidade de resolução de problemas e o raciocínio estratégico (GHIRARDI, 2010).

É relevante ainda saber que o role-play serve como um espelho da realidade quando relembra aos alunos a existência de pluralidade de interesses em relação à quase tudo que se debate hoje (GHIRARDI, 2012). Pontua-se ainda que este método desenvolve a oratória, o pensamento crítico etc., pois é sabido que a depender do interesse do cliente, pautará a elaboração de suas petições.

Cabe aduzir, por fim, que este método, apesar de se assemelhar com a prática de estágios supervisionados em escritórios ou órgãos públicos, bem como com a simulação, não é com eles confundido, pois, para a implementação do role-play, é exigido ao aluno a adoção de um papel específico, como defensor ou acusador, por exemplo, havendo uma preocupação com os meios que atingirão os fins buscados, o que não ocorre nos métodos citados acima. Nesses, o que importa são os mecanismos de desenvoltura, essenciais à relação harmônica entre autores variados (GHIRARDI, 2010).

A simulação, por sua vez, apresenta uma característica elementar que a sustenta, qual seja, a surpresa (GHIRARDI, 2012). Nesse caso, o seu ponto central consistirá na análise da relação entre os envolvidos na aprendizagem, por meio das ações, reflexões e interações 
interpessoais, a partir de problema fixado, destacando, como indicador da aplicação do ato de simular, a adequação de seu plano de ação às demandas decorrentes de diferentes pretensões (GHIRARDI, 2010). O engajamento em um caso fictício permite que os discentes apliquem o conhecimento teórico apreendido pelas doutrinas jurídicas e pelos professores, incentivando, dessa maneira, a formação de pesquisadores jurídicos, dada a necessidade de criação e reformulação de soluções para as demandas propostas (AMARAL JÚNIOR et al, 2016).

Quem implementa esse método de ensino tem como ponto favorável ainda a habilidade de interpretar e argumentar os fatos em discussão, traço crucial para o desenvolvimento da defesa de direitos e o posicionamento jurídico em uma lide processual (AMARAL JÚNIOR et al, 2016). Não se pode deixar de relatar que esse movimento de realizar atos hipotéticos, como audiências, sustentações orais e petições aperfeiçoa a desenvoltura do futuro operador do Direito, bem como valoriza o trabalho em equipe (AMARAL JÚNIOR et al, 2016).

Por fim, o método conhecido como PBL (problem-based learning) ou método baseado em problemas, também se parece com o role-play e a simulação, todavia oferece a liberdade nas soluções escolhidas, não se restringindo aos instrumentos presentes na esfera jurídica (GHIRARDI, 2012). Essa metodologia de ensino nasceu nos anos sessenta, a partir do curso de medicina, o qual utiliza casos e diagnósticos expressos por um tutor e conclui pelo melhor resultado (MACEDO; BARBOSA, 2016). A aprendizagem centrada em problemas propicia aos discentes o autogerenciamento na obtenção de conteúdo, incentivando também a exploração em áreas diversas do Direito, o que enriquece a solução encontrada para o impasse (MUSSI, 2010). Para Angelis Artur Mussi (2010), nesse método de ensino se aprende resolvendo problemas, dinâmica essa que permite o aluno "aprender a aprender".

Para que o método PBL surta os devidos efeitos, necessário é o cumprimento de alguns requisitos: os estudantes precisam ser dotados de algumas capacidades, a exemplo das capacidades de se comunicar, responsabilizar e organizar; os docentes devem aperfeiçoar as suas habilidades para se adequarem a essa metodologia; a grade curricular precisa constar o tempo necessário para o estudo dirigido e, ainda, é fundamental que exista um ambiente com infraestrutura apropriada para o desenvolvimento dessa forma de aprendizagem (MUSSI, 2010). 
Nessa situação, o esforço de solucionar impasses complicados, encontrados na realidade, ou simplesmente fictícios, não prescinde a noção de razoabilidade, porquanto o resultado proposto à questão discutida deve se revelar possível e admissível pelos participantes (GHIRARDI, 2012).

Vale ressaltar que, apesar da importância dos métodos acima narrados, na verdade, o que está acontecendo é certa dificuldade nas suas aplicações. Os motivos são vários, desde a não abertura das câmeras da maioria dos discentes, não permitindo assim um envolvimento real com o docente e os demais alunos, a redução de interação e de comprometimento do aprendiz com a aula ministrada, impedindo a sua plena participação, até os contratempos eventualmente ocorridos em razão de instabilidade de conexão de internet que afeta tanto discentes como docentes.

\section{CONCLUSÃO}

A arte do saber, desde os primórdios, já representava a necessidade do ser humano de conhecer os seus próprios desejos, emoções e comportamentos, refletindo o que ainda hoje, porém em diferentes níveis, percebe-se na área acadêmica. O fenômeno da globalização e fruto dela, a evolução da sociedade com os novos postos de trabalho, e o surgimento da internet, acarretaram mudanças significativas em diversas áreas da vida dos cidadãos, dentre elas, o ensino.

O modo de ensino deixou de ser exclusivamente baseado na aprendizagem tradicional, hermética, caracterizada pela hierarquia entre os participantes da sala de aula e pela forma expositiva de lecionar, para configurar um modelo mais inclusivo e aberto de aprendizagem, trazendo para o desenvolvimento educacional uma abordagem mais democrática. É nesse momento de transição que surgem os métodos de ensino participativo.

Essa nova sistemática inclusiva de formação do conhecimento destaca-se por posicionar a pessoa do aluno no protagonismo do processo pedagógico, admitindo a presença do diálogo entre o professor e o aluno, o acolhimento deste, juntamente com as suas particularidades e ainda 
o uso de modernos mecanismos metodológicos (como os vídeos do youtube e o kahoot), isso tudo de forma razoável e equilibrada. Além de facilitador da transmissão do conhecimento, a figura do professor, igualmente, recebe uma nova função na cadeia acadêmica, qual seja, a de conservar a individualidade dos discentes na medida em que são valorizadas e aproveitadas as potencialidades de cada um.

As ferramentas de ensino participativo tratadas nesse trabalho - métodos de ensino ativo o diálogo socrático, o método do caso, o hole-play, a simulação e o PBL - representam hipóteses as quais os docentes poderão utilizar em suas aulas ou palestras para permitir a arquitetura de estratégias e a solução das contingências apontadas pelo orientador pedagógico. Cada uma dessas técnicas traz consigo determinado diferencial, entretanto, todas correspondem à finalidade para a qual foi criada, qual seja, tornar o aluno protagonista do processo de ensino.

A reflexão apresentada nesse trabalho ainda contribui para a redução dos danos oriundos da situação pandêmica atual, apresentando - por meio de ferramentas que viabilizam encontros à distância e a manutenção de interação entre os envolvidos no processo de aprendizagem como: as plataformas de videoconferência (Google Meet, Zoom, Microsoft Yeams etc.), espaços para disponibilizar vídeos, podcasts, textos, links (Moodle, YouTube etc.) - estratégias e novos métodos de ensino, os quais corroboram, em certa medida, para a difusão do conhecimento entre os cidadãos. Esse desafio, enfrentado mais fortemente nos últimos dez anos, foi exponencialmente incrementado com a Pandemia vivida atualmente, dada a rápida necessidade de migração do ambiente acadêmico para o cenário remoto e a incerteza sobre quando e como as aulas presenciais serão retomadas.

Desta forma, percebe-se que a sociedade contemporânea se estrutura de forma que, em poucas semanas, toda a organização das relações sociais e econômicas precisa ser repensada e se adequar a um novo cenário, como o da pandemia da COVID 19, bem como às exigências sociais advindas do progresso tecnológico e da ânsia dos estudantes por transformações que considerem a prevalência dos direitos humanos. Pode-se concluir, portanto, que a forma mais democrática de ensino do Direito é aquela que conseguir reunir um pouco de cada um dos métodos vistos anteriormente, consistindo no verdadeiro desafio da docência jurídica ainda a ser alcançado no século XXI. 


\section{REFERÊNCIAS}

ALENCAR, Wladimir Cerveira de; SALES, Ana Paula Correa. Experiências de estratégias pedagógicas no ensino jurídico sob uma nova perspectiva. Revista do Curso de Direito UNIABEU. vol. 4, n. 1, P. 79-96, Janeiro-Dezembro, 2015. Disponível em: https://revista.uniabeu.edu.br/index.php/rcd/article/view/1728

ALLESSANDRINI, Cristina Dias. O DESENVOLVIMENTO DE COMPETÊNCIAS E A PARTICIPAÇÃO PESSOAL NA CONSTRUÇÃO DE UM NOVO MODELO EDUCACIONAL. In: PERRENOUD, Philippe; THURLER, Monica Gather; MACEDO, Lino de; MACHADO, Nílson José; ALLESSANDRINI, Cristina Dias. As competências para ensinar no século XXI: A formação dos professores e o desafio da avaliação. Porto Alegre: Artmed, 2002, p. 157-175.

AMARAL JÚNIOR, Alberto do et al. O modelo de ensino participativo no Direito Internacional: relato de uma experiência. Revista Direito GV, v. 12, n. 3, p. 632-647, 2016. Disponível em: https://www.scielo.br/pdf/rdgv/v12n3/1808-2432-rdgv-12-03-0632.pdf. Acesso em: 29 mar. 2021.

BURBULES, Nicholas C.; TORRES, Carlos Alberto. Globalização e educação: uma introdução. Globalização e Educação: perspectivas críticas, p. 11-26, 2000.

DEMO, Pedro. Habilidades e competências no século XXI. 3. ed. Porto Alegre: Mediação, 2012.

FERNANDEZ, Atahualpa; FERNANDEZ, Marly. Sobre a dissonância cognitiva, o autoengano e a ignorância autoimposta. Revista 50, ano XIV, Lima/Perú. 2017. Disponível em:

http://www.derechoycambiosocial.com/revista050/SOBRE A DISSONANCIA COGNITIVA.p df. Acesso em: 09. dez. 2019.

FRANCO, Aline Fonseca; COSTA FILHO, José de Oliveira. As metodologias ativas como instrumento para se atingir uma aprendizagem significativa, reflexiva e interdisciplinar no ensino jurídico. Colloquium Socialis, Presidente Prudente, v.1, n. Especial, p. 510-516, 2017.

Disponível em:

http://www.unoeste.br/site/enepe/2016/suplementos/area/Socialis/Direito/AS\%20METODOLOG IAS\%20ATIVAS\%20COMO\%20INSTRUMENTO\%20PARA\%20SE\%20ATINGIR\%20UMA \%20APRENDIZAGEM\%20SIGNIFICATIVA,\%20REFLEXIVA\%20E\%20INTERDISCIPLIN AR\%20NO\%20ENSINO\%20JUR\%C3\%8DDICO.pdf. Acesso em: 12 dez. 2019.

GHIRARDI, José Garcez. O instante do encontro: questões fundamentais para o ensino jurídico. São Paulo: Fundação Getúlio Vargas, 2012.

GHIRARDI. José Garcez (coord). Avaliação e métodos de ensino no Direito. Cadernos Direito GV. São Paulo, vol. 7, n. 5, p., 2010. Disponível em: https://bibliotecadigital.fgv.br/dspace/bitstream/handle/10438/7851/Caderno\%20Direito\%20GV \%20-\%2037\%20-\%20site.pdf. Acesso em: 14 dez. 2019. 
LIMA, Stephane Hilda Barbosa. Formação jurídica, metodologias ativas de ensino e a experiência da graduação da escola de direito de São Paulo (FGV Direito SP). 2018. 175 f. Dissertação (Mestrado) - Faculdade de Direito, Universidade Federal do Ceará, Fortaleza-CE, 2018. Disponível em: http://repositorio.ufc.br/bitstream/riufc/33352/1/2018_dis_shblima.pdf. Acesso em: 19 mar. 2021.

MACEDO, Tatiane Alves; BARBOSA, Maísa. Aplicabilidade da metodologia do aprendizado centrado em problemas (problem based learnig-PBL) no curso de Direito. In: Anais Colóquio Estadual de Pesquisa Multidisciplinar (ISSN-2527-2500) \& Congresso Nacional de Pesquisa Multidisciplinar, Mineiros/GO, 2016.

MACHADO, Anna Rachel. (RE-)CONFIGURAÇÕES DO TRABALHO DO PROFESSOR CONSTRUÍDAS NOS E PELOS TEXTOS: A PERSPECTIVA METODOLÓGICA DO GRUPO ALTER-LAEL. In: CRISTOVÃO, Vera Lúcia; ABREUTARDELLI, Lília S. (Org.) Linguagem e educação: o trabalho do professor em uma nova perspectiva. Campinas: Mercado das Letras, 2009. p.31-69.

MUSSE, Luciana Barbosa. Novas perspectivas para ensinar direito: o ensino jurídico por intermédio de habilidades. Revista Direito GV, v. 2, n. 2, p. 249-253, 2006.

MUSSI, Angelis Artur. Aplicação do PBL no ensino do Direito. Vox Forensis, Espírito Santo do Pinhal, v. 3, n. 2, Abr./Jun. 2010. Disponível em: https://core.ac.uk/download/pdf/16023143.pdf. Acesso em: 29 mar. 2021.

PEREIRA JÚNIOR, Antonio Jorge Ferreira; MELO, Felipe Antônio de Castro Bezerra Morais. A relevância da prudência nos métodos de ensino participativo para a didática jurídica.

Conhecimento \& Diversidade, Niterói, v.10, n. 20, p. 116-128, 2018. Disponível em:https://www.revistas.unilasalle.edu.br/index.php/conhecimento_diversidade/article/view/34. Acesso em: 13 dez. 2019.

PERRENOUD, Philippe. 10 novas competências para ensinar. Porto Alegre: Artmed, 2000. PIMENTA, Selma Garrido; ANASTASIOU, Léa das Graças Camargos. Docência no Ensino Superior. 5. ed. São Paulo: Cortez, 2014.

RAMOS, Edith Maria Barbosa. O ensino jurídico e a metáfora do espaço. Revista Opinião Jurídica (Fortaleza), v. 6, n. 10, p. 46-55, 2008. 